\title{
Free vibration analysis of eccentric and concentric isotropic stiffened plate using ANSYS
}

\author{
Harun Rashid Siddiqui* and Vaibhav Shivhare
}

Department of Mechanical Engineering, Madhav Institute of Technology and Science, Gwalior, India

\begin{tabular}{ll} 
A R T I C L E I N F O & A B S T R A C T \\
\cline { 2 - 3 } $\begin{array}{l}\text { Article history: } \\
\text { Received 6 April, } 2015\end{array}$ In the present world stiffeners are widely used to fulfill the requirement of high stiffness. \\
$\begin{array}{l}\text { Accepted 20 July } 2015 \\
\text { Available online }\end{array}$ Stiffened plates are used in most of the mechanical structures. In this paper free vibration \\
20 July 2015 & $\begin{array}{l}\text { analysis of eccentric and concentric stiffened isotropic plate with central stiffener and double } \\
\text { stiffener has been studied and effect of various parameters such as boundary conditions, aspect }\end{array}$ \\
\hline Keywords: & ratio on non-dimensional frequency parameter of plate are investigated. Comparison of non- \\
Free vibration & dimensional frequency parameter for eccentric and concentric isotropic stiffened plate with \\
FEM & effect of number of stiffener at different mode shapes, aspect ratios and boundary conditions \\
Stiffened plate & is studied using ANSYS parametric design language (APDL) code. A ten nodded element \\
Natural frequency & (SOLID 187) from ANSYS element library is used for the discretization of proposed stiffened \\
Aspect ratio & isotropic plate. Convergence study of developed model with respect to the number of modes \\
Boundary conditions & has been done and results are compared from the related available published literature. Non \\
Central stiffener & dimensional frequencies are higher for fully clamped boundary condition for eccentric and \\
Double stiffener & concentric stiffened isotropic plate in comparison to other boundary condition. It is also seen \\
& that non dimensional frequencies are increases in a moderate value for eccentric and concentric \\
isotopic plate with double stiffener in comparison to the central stiffener.
\end{tabular}

(C) 2015 Growing Science Ltd. All rights reserved.

\section{Introduction}

In many real life situations, we face vibrations in machines, turbine blades, structures like highway bridges, elevated roadways, lock gates, box girders, plate girders etc. and as well as in aerospace application, Research into stiffened plates has been a subject of interest for many years. Extensive efforts by many researchers have been devoted to investigate the response of the stiffened plates. The research accomplished on stiffened plates can be classified into two categories, analysis and design. In this work the initiation has been taken to carry on analysis of free vibration of isotropic stiffened plates by ANSYS 14 software package and the results has been validated with the literatures available. The extensive review on plate vibration can be found in the literature provided. 
Asku and Ali (1976) presented a numerical algorithm procedure for equally spaced stiffeners. The method is based on the variational principles in addition with finite difference techniques to determine the natural frequency of the structure. Free vibration characteristics of rectangular stiffened plates with a single stiffener have been examined by using the finite difference method (Ebirim et al., 2014). The free vibration of simply supported plate with one free edge was tested in detail and formulation of model is based on Ibearugbulem's shape function and Ritz method. In the study, Ibearugbulem's shape function was added into the potential energy functional, was reduced to obtain the fundamental natural frequency.

Sadek et al. (2000) studied a refined higher-order displacement model for the study of the behavior of concentrically and eccentrically stiffened laminated plates based on finite element discretization. They used the nine-noded isoparametric plate element with seven degrees of freedom at each node and for stiffener three-noded isoparametric beam element with four degrees of freedom at each node was used. The results show the flexibility in the position of stiffeners with the choice of flexible mesh size. Hamedani et al. (2012) studied the vibration analysis of stiffened plates, using both conventional and super finite element methods. An effective use of Mindlin plate and Timoshenko beam theories has been investigated to formulate the plate and stiffeners, respectively and have been used for free vibration studies of different geometries and materials (e.g. Samaei et al., 2015). Eccentricity of the stiffeners is considered and they are not limited to be placed on nodal lines. Therefore, any configuration of plate and stiffeners can be modeled. Numerical examples are proposed to study the accuracy and convergence characteristics of the super elements.

Holopainen (1995) proposed a new finite element model for the free vibration analysis of eccentrically stiffened plate. In this model, a mixed interpolation of tension components is used for both the plate bending and stiffener elements to free shear locking. Klitchief and Belgrade (1949) analyzed the stability of infinitely long, simply supported, transverse stiffened plates under uniform compression and lateral load. An extreme motivation of the work was to assess for design rules used in naval architecture. Even though their objective was to analyze eccentric stiffeners. Their approach appears to be valid only for the concentric case. In the eccentric case, difficulties appear over the concentric configuration in the coupling between the in-plane and out-of-plane displacements, by which results in an increase of the order of the differential equations for the structure which has been ignored in the analysis of their solution.

Long (1969) performed structural analysis for the computational evaluation of the natural frequency of simply supported stiffened plates in the longitudinal direction by using stiffness method. They illustrated the method for the analysis of a plate with one longitudinal stiffener and a plate with one longitudinal and one transverse stiffener. Mukherjee and Mukhopadhyay (1986) investigated the opinions of different approaches for vibration analysis of conventional stiffened plate problems. Many of these approaches can be employed together with the finite element method (FEM). The governing differential equations can be derived for the structure by assuming the stiffeners are symmetric about the mid-plane of the plate and ignored their torsional stiffness and shear deformation. A displacement function satisfying the boundary condition is later substituted into the governing differential equations by which the resulting equations was transformed into ordinary differential equations with constant coefficients that are solved by a finite difference.

Mukhopadhyay (1989) used a finite-difference method for the detailed examination of the structure. Olson and Hazell (1977) examined results from a theoretical and experimental comparison study of the vibrations of four integrally machined rib-stiffened plates. In that study, effective use of most advanced analysis tools available today namely, the finite element method with high precision elements for the theory and real-time laser holography for the experiment was employed. Integral rib-stiffened plates are becoming common in aerospace applications where it is desired to have natural frequencies as high as possible for a given plate weight. Such configurations may be analyzed satisfactorily with orthotropic plate theory when the density of stiffeners is high. Qing et al. (2006) developed a fictitious 
mathematical model for free vibration analysis of stiffened laminated plates by separate consideration of plate and stiffeners. By using the semi-analytical solution of the state-vector equation theory, the method accounts for the compatibility of displacements and stresses on the interface between the plate and stiffeners, the transverse shear deformation, and naturally the rotary inertia of the plate and stiffeners. Meanwhile, there is no restriction on the thickness of plate and the height of stiffeners.

Samanta and Mukhopadhyay (2004) studied the development of a new stiffened shell element and subsequent application of this element in determining natural frequencies and mode shapes of the different stiffened structures. Wah (1964) used an energy model approach to analyze equally spaced, concentric stiffeners with identical cross-sectional properties. At a first stage, a numerical procedure for the computational evaluation of the fundamental frequency is presented. The strain energy of the designed plate/stiffener elements is derived in terms of generalized in- and out-of-plane displacement functions and mathematical programming is used to determine the lowest natural frequency. The prediction of a described algorithm is verified with other numerical procedures like finite-element, finite-strip and finite-difference methods. Results are then presented, by showing the influence of the plate/stiffener geometric parameters on the fundamental frequency of structure with different concentric and eccentric stiffening configurations.

Thinh and Khoa (2008) studied free vibration analysis of stiffened laminated plate based on Mindlin's deformation plate theory in which a new 9-noded element is used. Wu and Liu (1988) studied detail examination of the free vibration of stiffened plates with elastically edges restrained and intermediate stiffeners has been carried out by application of the Rayleigh-Ritz method. Zeng and Bert (2001) studied a differential quadrature analysis of free vibration of plates with eccentric stiffeners. In their work, the plate and the stiffeners are presented separately. Simultaneous governing differential equations are derived from the plate dynamic equilibrium, the stiffener dynamic equilibrium, and equilibrium and compatibility conditions along the interface of a plate segment and a stiffener. In this paper free vibration analysis of eccentric and concentric stiffened isotropic plates with central stiffener and double stiffener is studied numerically using the ANSYS finite element code and effect of various parameters such as boundary conditions, aspect ratio on non-dimensional frequency parameter of plate are investigated.

\section{Method and Material Properties}

Figs. (1-4) show the geometry of different stiffened plates which is studied in this research. The equation of motion for free vibration analysis of elastic system undergoing displacement can be expressed in matrix form.

$$
[K]\{u\}+[M]\{\ddot{u}\}=0,
$$

where $[\mathrm{K}]$ and $[\mathrm{M}]$ are overall stiffness matrix and $\{\mathrm{u}\}$ is displacement vector.

FEA involves three stages of activity:

\section{Preprocessing \\ 2. Processing \\ 3. Post processing}

SOLID187 element (Fig. 5) is a higher order 3-D, 10-node element. SOLID187 has a quadratic displacement behavior and is well suited to modeling irregular meshes (such as those produced from various CAD/CAM systems). The element is defined by 10 nodes having three degrees of freedom at each node: translations in the nodal $\mathrm{x}, \mathrm{y}$, and $\mathrm{z}$ directions. The element has plasticity, hyperelasticity, creep, stress stiffening, large deflection, and large strain capabilities. 


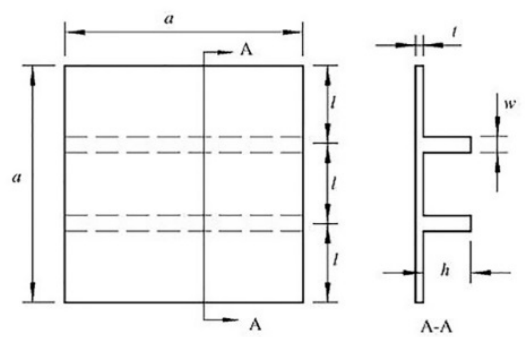

Fig. 1. Geometry of eccentrically stiffened isotropic plate with double stiffener

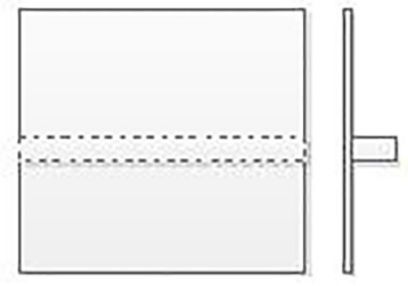

Fig. 2. Geometry of eccentrically stiffened isotropic plate

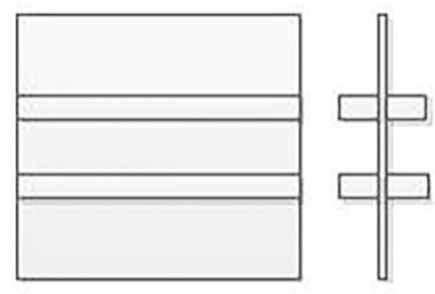

Fig. 3. Geometry of concentrically stiffened with central stiffener isotropic plate with double stiffener

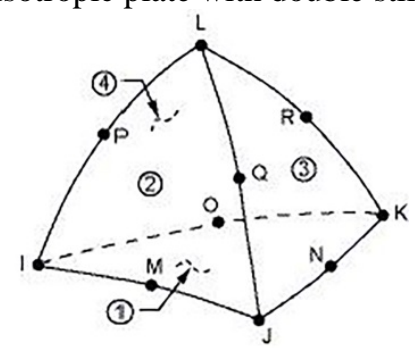

Fig. 4. Geometry of concentrically stiffened isotropic plate with central stiffener

Fig. 5. SOLID 187 element

The material properties and geometric parameters for eccentrically stiffened isotropic plates (i.e. Figs. 2 to 4 ) with central stiffener are as follows: $E=68.9 \mathrm{GPa}, v=0.3, \rho=2670 \mathrm{~kg} / \mathrm{m}^{3}, a=0.2032 \mathrm{~m}$, $l=0.1016 \mathrm{~m}, t=0.00127 \mathrm{~m}, w=0.002286 \mathrm{~m}, h=0.01778 \mathrm{~m}$.

\section{Numerical results and discussion}

Various boundary conditions of eccentrically and concentrically stiffened isotropic plate with different aspect ratios and affect number of stiffeners are investigated. Boundary conditions along the edges are described by the alphabets so that C-C-C-C indicates a stiffened plate with edge $\mathrm{x}=0$ clamped, edge $\mathrm{y}=0$ clamped, edge $\mathrm{x}=\mathrm{a}$ clamped and edge $\mathrm{y}=\mathrm{a}$ clamped in which $\mathrm{x}, \mathrm{y}, \mathrm{z}$ are co-ordinates axes.

\subsection{Convergence study}

To demonstrate the efficiency of ANSYS software package an eccentrically stiffened isotropic plate with double stiffener has been considered. The material properties and geometric parameters shown in Fig. 1 are as follows: $E=68.9 \mathrm{GPa}, v=0.3, \rho=2670 \mathrm{~kg} / \mathrm{m}^{3}, a=0.2032 \mathrm{~m}, l=0.6773 \mathrm{~m}, t=0.00127$ $\mathrm{m}, w=0.002286 \mathrm{~m}, h=0.01778 \mathrm{~m}$.

An eccentrically stiffened isotropic plate with double stiffener (Fig. 1) which is a previously reported experimental and theoretical example (Olson \& Hazell, 1977; Zeng \& Bert, 2001; Qing \& Liu, 2006), are selected as the first example to validate present method. The results, as listed in Table 1, show that reasonable convergence has been achieved with relatively small decrements in the first five frequencies, never as much as $1 \%$, between corresponding value for mesh size $82 \times 82,1$ and mesh size $92 \times 92,1$. It is obvious (see Table 2 and Fig. 6.) that the first four modes are in acceptable range. The same trend was seen in Olson \& Hazell (1977) and Zeng \& Bert (2001). Note that natural frequencies are obtained by using ANSYS (APDL) are lower for first two modes and higher for remaining two modes than those of FEM (Olson \& Hazell, 1977). 
Table 1. Natural frequencies $(\mathrm{Hz})$ for eccentrically stiffened isotropic plate with double stiffeners and clamped at edges

\begin{tabular}{lcccccc}
\hline \multicolumn{2}{c}{ Mesh size } & \multicolumn{5}{c}{ Mode } \\
\hline Plate & Stiffeners & Mode 1 & Mode 2 & Mode 3 & Mode 4 & Mode 5 \\
\hline $11 \times 11,1$ & $1 \times 11,8$ & 1806.5 & 1967.9 & 1999.0 & 3121.6 & 3539.6 \\
$22 \times 22,1$ & $2 \times 22,8$ & 1054.9 & 1397.4 & 1527.6 & 1637.5 & 1799.9 \\
$33 \times 33,1$ & $2 \times 33,8$ & 974.93 & 1287.7 & 1405.0 & 1475.2 & 1647.8 \\
$42 \times 42,1$ & $2 \times 42,8$ & 963.32 & 1267.8 & 1382.6 & 1440.5 & 1613.2 \\
$52 \times 52,1$ & $2 \times 52,8$ & 959.83 & 1261.6 & 1375.2 & 1430.5 & 1604.2 \\
$62 \times 62,1$ & $2 \times 62,8$ & 958.15 & 1258.3 & 1371.7 & 1425.3 & 1599.5 \\
$72 \times 72,1$ & $2 \times 72,8$ & 957.24 & 1256.7 & 1370.1 & 1422.4 & 1596.8 \\
$82 \times 82,1$ & $2 \times 82,8$ & 956.65 & 1255.4 & 1369.0 & 1420.2 & 1595.0 \\
$92 \times 92,1$ & $2 \times 92,8$ & 956.38 & 1255.1 & 1368.4 & 1419.5 & 1594.1 \\
\hline
\end{tabular}

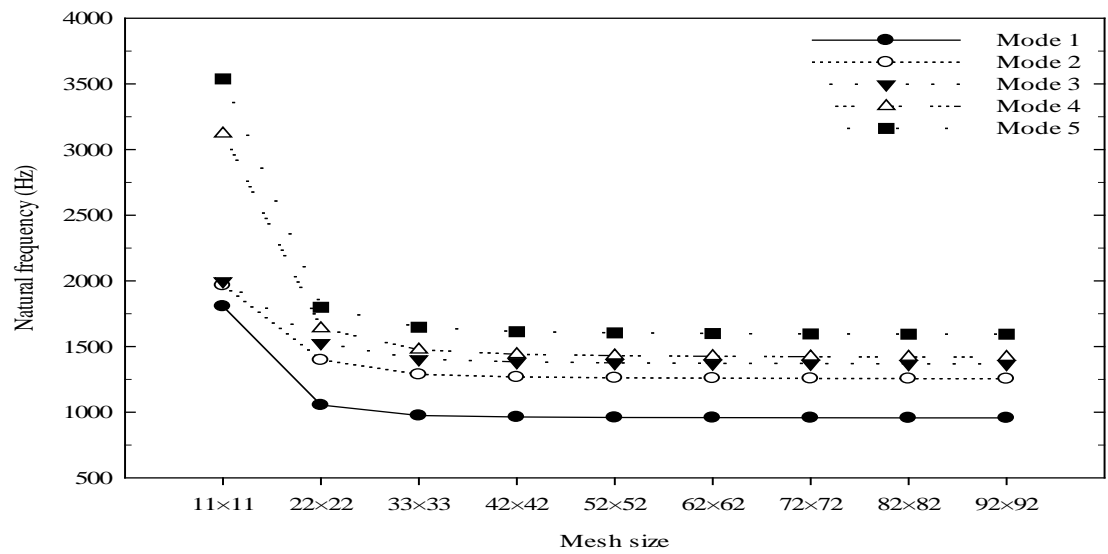

Fig. 6. Convergence study of the element used for eccentrically stiffened isotropic plate with double stiffener

Table 2. Comparison of natural frequencies $(\mathrm{Hz})$ for eccentrically stiffened isotropic plate with double stiffener and clamped at edges.

\begin{tabular}{lllll}
\hline & \multicolumn{4}{c}{ Mode number (Error \% = 100 · (Present-Ref.)/Ref.) } \\
Methods & Mode 1 & Mode 2 & Mode 3 & Mode 4 \\
\hline Experimental, Olson and Hazell (1977) & $909(5.242)$ & $1204(4.269)$ & $1319(3.790)$ & $1506(-5.697)$ \\
FEM, Olson and Hazell (1977) & $965.3(-0.896)$ & $1272.3(-1.328)$ & $1364.3(0.344)$ & $1418.1(0.148)$ \\
DQa, Zeng and Bert (2001) & $915.9(4.449)$ & $1242.2(1.062)$ & $1344.4(1.829)$ & $1414.1(0.431)$ \\
Qing et al. (2006) & $931.5(2.699)$ & $1220.9(2.825)$ & $1331.8(2.793)$ & $1403.3(1.204)$ \\
\hline Present & 956.65 & 1255.4 & 1369.0 & 1420.2 \\
\hline
\end{tabular}

Table 3 and Fig. 7 show the variation of first five mode of non-dimensional frequency parameter at (CCCC, SSSS, CSCS, CFCF,CFFF) for eccentrically stiffened isotropic square plate with double stiffener and Table 4 and Fig. 8 shows the variation of first five mode of non-dimensional frequency parameter at (CCCC, SSSS, CSCS, CFCF,CFFF) for concentrically stiffened isotropic square plate with double stiffener. In both Tables the frequencies for all mode shapes increases at different boundary conditions and the highest values of non-dimensional frequencies are obtained for CCCC boundary condition and the lowest values of non-dimensional frequencies are obtained for CFFF boundary condition, also there is small difference between the values of frequencies for CCCC vs CSCS boundary conditions in comparison to the rest of the boundary conditions. Table 5 and Fig. 9 show the variation of first five mode of non-dimensional frequency parameter at (CCCC, SSSS, CSCS, CFCF and CFFF) for eccentrically stiffened isotropic square plate with central stiffeners. Table 6 and Fig 10 shows the variation of first five mode of non-dimensional frequency parameter at (CCCC, SSSS, CSCS, CFCF and CFFF) for concentrically stiffened isotropic square plate with central stiffener. In both Tables and figures the non-dimensional frequencies for all modes shape increases at different boundary conditions, and the highest values of non-dimensional frequencies are obtained for the CCCC 
boundary condition and the lowest values are obtained for the CFFF boundary conditions. Also there is small difference between the values of frequencies for the CCCC vs CSCS boundary conditions in comparison with the rest of the boundary conditions.

Table 3. Variation of Non dimensional frequency parameter $\left(\Omega=\omega a^{2} \sqrt{\frac{\rho h}{D}}\right)$ for eccentrically stiffened square plate with double stiffener at different boundary conditions

\begin{tabular}{lccccc}
\hline MODE & Mode 1 & Mode 2 & Mode 3 & Mode 4 & Mode 5 \\
\hline CCCC & 20.23 & 26.557 & 28.958 & 30.041 & 33.73 \\
SSSS & 17.32 & 18.876 & 20.641 & 24.827 & 27.33 \\
CSCS & 18.35 & 20.927 & 26.263 & 26.851 & 28.76 \\
CFCF & 6.29 & 6.621 & 12.925 & 13.007 & 20.69 \\
CFFF & 3.552 & 3.620 & 7.508 & 7.92 & 8.456 \\
\hline
\end{tabular}

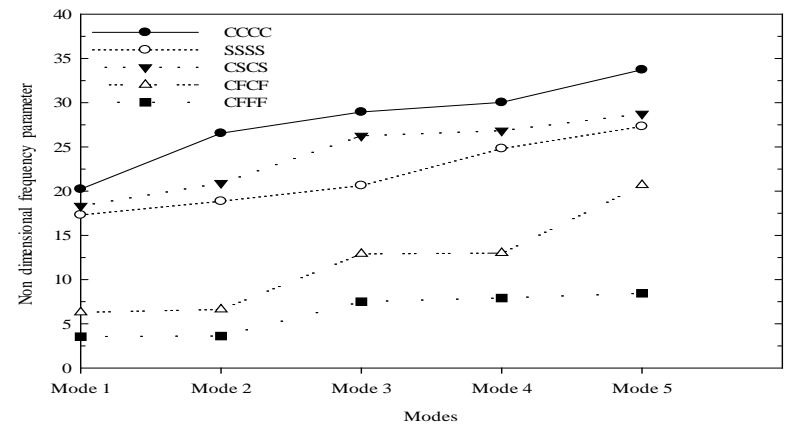

Fig. 7. Variation of Non dimensional frequency parameter $\left(\Omega=\omega a^{2} \sqrt{\frac{\rho h}{D}}\right)$ for eccentrically stiffened isotropic square plate with double stiffener at different boundary conditions

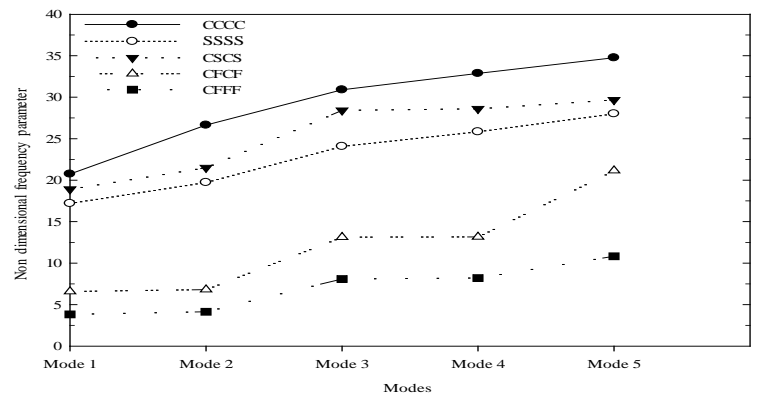

Fig. 8. Variation of non-dimensional frequency parameter ( $\Omega=\omega a^{2} \sqrt{\frac{\rho h}{D}}$ ) for concentrically stiffened isotropic square plate with double stiffener at different boundary conditions

Table 4. Variation of non-dimensional frequency parameter $\left(\Omega=\omega a^{2} \sqrt{\frac{\rho h}{D}}\right)$ for concentrically stiffened isotropic plate with double stiffener at different boundary conditions

\begin{tabular}{lccccc}
\hline MODE & Mode 1 & Mode 2 & Mode 3 & Mode 4 & Mode 5 \\
\hline CCCC & 20.743 & 26.640 & 30.891 & 32.873 & 34.756 \\
SSSS & 17.196 & 19.738 & 24.082 & 25.842 & 28.006 \\
CSCS & 18.923 & 21.510 & 28.421 & 28.605 & 29.675 \\
CFCF & 6.578 & 6.807 & 13.121 & 13.161 & 21.159 \\
CFFF & 3.831 & 4.141 & 8.086 & 8.203 & 10.824 \\
\hline
\end{tabular}

Table 5. Variation of non-dimensional frequency parameter $\left(\Omega=\omega a^{2} \sqrt{\frac{\rho h}{D}}\right)$ for eccentrically stiffened isotropic square plate with central stiffener at different boundary conditions

\begin{tabular}{lccccc}
\hline MODE & Mode 1 & Mode 2 & Mode 3 & Mode 4 & Mode 5 \\
\hline CCCC & 12.388 & 15.466 & 18.650 & 20.363 & 27.680 \\
SSSS & 9.441 & 12.134 & 15.504 & 17.014 & 23.752 \\
CSCS & 10.064 & 12.836 & 17.046 & 18.400 & 26.502 \\
CFCF & 4.438 & 4.959 & 10.954 & 11.180 & 13.272 \\
CFFF & 1.564 & 2.574 & 5.327 & 5.696 & 7.873 \\
\hline
\end{tabular}




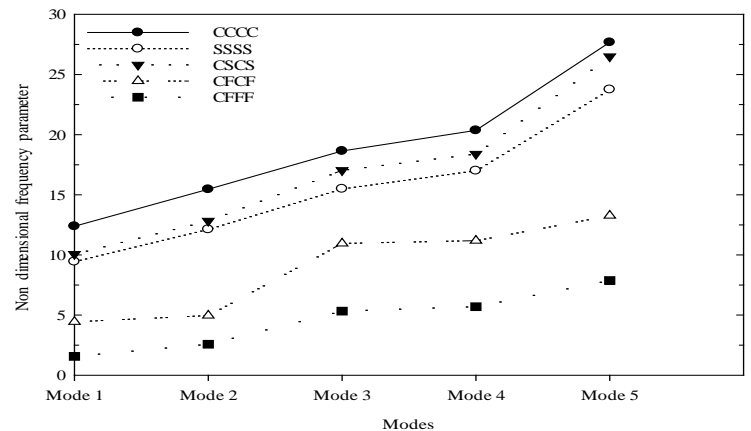

Fig. 9. Variation of non-dimensional frequency parameter ( $\Omega=\omega a^{2} \sqrt{\frac{\rho h}{D}}$ ) for eccentrically stiffened isotropic square plate with central stiffener at different boundary conditions

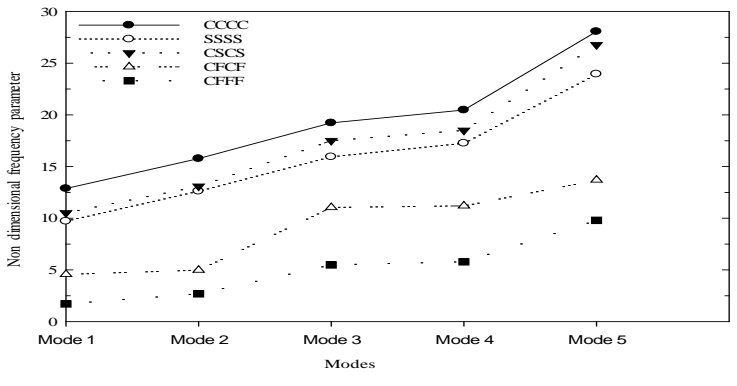

Fig. 10. Variation of non-dimensional frequency parameter $\left(\Omega=\omega a^{2} \sqrt{\frac{\rho h}{D}}\right)$ for concentrically stiffened isotropic square plate with central stiffener at different boundary conditions

Table 6. Variation of non-dimensional frequency parameter $\left(\Omega=\omega a^{2} \sqrt{\frac{\rho h}{D}}\right)$ for concentrically stiffened isotropic square plate with central stiffener at different boundary conditions

\begin{tabular}{lccccc}
\hline MODE & Mode 1 & Mode 2 & Mode 3 & Mode 4 & Mode 5 \\
\hline CCCC & 12.876 & 15.775 & 19.226 & 20.473 & 28.065 \\
SSSS & 9.712 & 12.628 & 15.954 & 17.265 & 23.957 \\
CSCS & 10.517 & 13.105 & 17.519 & 18.509 & 26.779 \\
CFCF & 4.567 & 4.975 & 11.038 & 11.190 & 13.704 \\
CFFF & 1.713 & 2.686 & 5.484 & 5.781 & 9.794 \\
\hline
\end{tabular}

Table 7. Variation of first five non-dimensional frequency parameter $\left(\Omega=\omega a^{2} \sqrt{\frac{\rho h}{D}}\right.$ ) for eccentrically stiffened isotropic plate with central stiffener and clamped at edges with different aspect ratio

\begin{tabular}{clllll}
\hline Aspect ratio(a/b) & Mode 1 & Mode 2 & Mode 3 & Mode 4 & Mode 5 \\
\hline 0.5 & 5.290 & 5.747 & 10.441 & 11.553 & 11.679 \\
1 & 12.388 & 15.466 & 18.650 & 20.363 & 27.680 \\
1.5 & 24.345 & 28.368 & 30.353 & 36.832 & 39.490 \\
2 & 41.053 & 41.982 & 48.164 & 58.099 & 59.970 \\
\hline
\end{tabular}

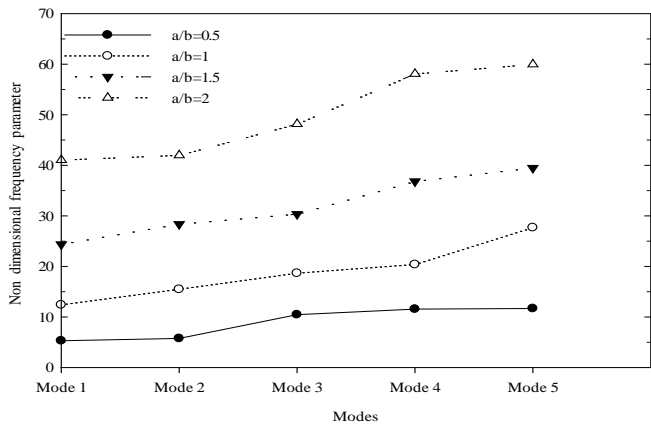

Fig. 11. Variation of first five non-dimensional frequency parameter ( $\Omega=\omega a^{2} \sqrt{\frac{\rho h}{D}}$ ) for eccentrically stiffened isotropic plate with central stiffener and clamped at edges with different aspect ratio

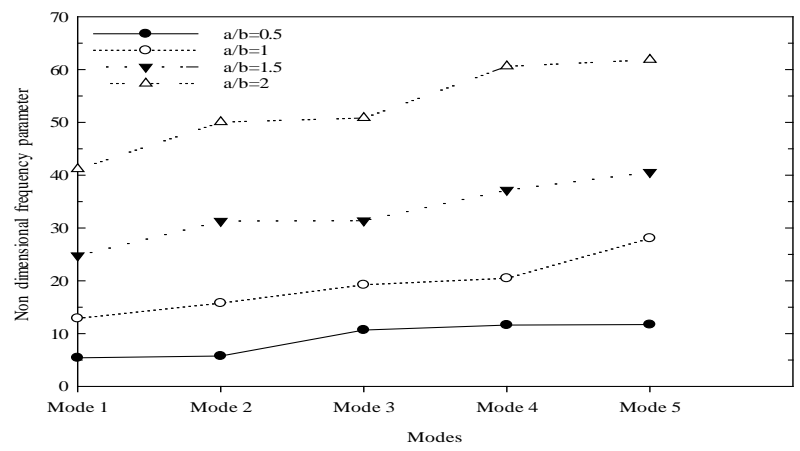

Fig. 12. Variation of first five non-dimensional frequency parameter ( $\Omega=\omega a^{2} \sqrt{\frac{\rho h}{D}}$ ) for concentrically stiffened isotropic plate with central stiffener and clamped at edges with different aspect ratio 
Table 8. Variation of first five non-dimensional frequency parameter ( $\left.\Omega=\omega a^{2} \sqrt{\frac{\rho h}{D}}\right)$ for concentrically stiffened isotropic plate with central stiffener and clamped at edges with different aspect ratio

\begin{tabular}{cccccc}
\hline Aspect ratio(a/b) & Mode 1 & Mode 2 & Mode 3 & Mode 4 & Mode 5 \\
\hline 0.5 & 5.402 & 5.756 & 10.669 & 11.607 & 11.718 \\
1 & 12.876 & 15.775 & 19.226 & 20.473 & 28.065 \\
1.5 & 24.770 & 31.339 & 31.408 & 37.203 & 40.592 \\
2 & 41.165 & 50.072 & 50.846 & 60.631 & 61.873 \\
\hline
\end{tabular}

Table 9. Variation of first five non-dimensional frequency parameter ( $\Omega=\omega a^{2} \sqrt{\frac{\rho h}{D}}$ ) for eccentrically stiffened isotropic plate with double stiffener and clamped at edges with different aspect ratio

\begin{tabular}{clllll}
\hline Aspect ratio(a/b) & Mode 1 & Mode 2 & Mode 3 & Mode 4 & Mode 5 \\
\hline 0.5 & 7.588 & 8.861 & 9.681 & 14.068 & 14.659 \\
1 & 20.23 & 26.557 & 28.958 & 30.041 & 33.73 \\
1.5 & 35.863 & 45.544 & 48.077 & 50.967 & 62.624 \\
2 & 47.527 & 61.713 & 74.354 & 78.899 & 95.138 \\
\hline
\end{tabular}

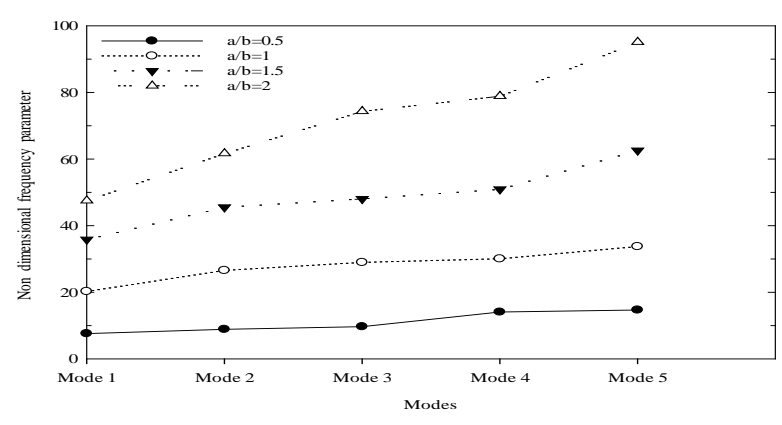

Fig. 13. Variation of first five non-dimensional frequency parameter ( $\Omega=\omega a^{2} \sqrt{\frac{\rho h}{D}}$ ) for eccentrically stiffened isotropic plate with double stiffener and clamped at edges with different aspect ratio

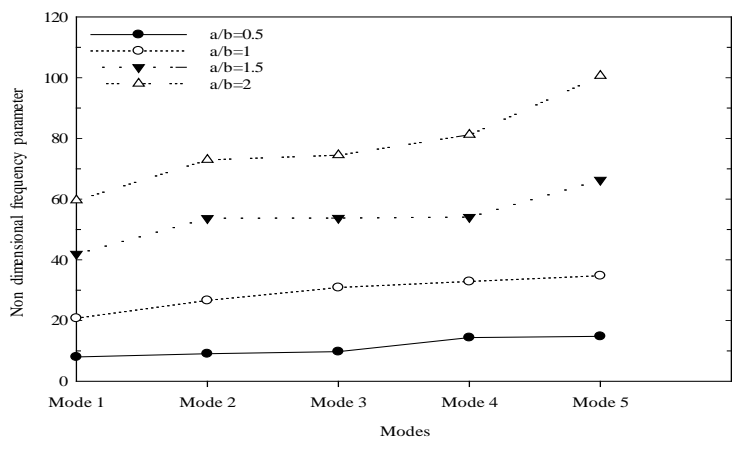

Fig. 14. Variation of first five non-dimensional frequency parameter ( $\Omega=\omega a^{2} \sqrt{\frac{\rho h}{D}}$ ) for concentrically isotropic stiffened plate with double stiffener and clamped at edges with different aspect ratio

Table 10. Variation of first five non-dimensional frequency parameter ( $\left.\Omega=\omega a^{2} \sqrt{\frac{\rho h}{D}}\right)$ for concentrically isotropic stiffened isotropic plate with double stiffener and clamped at edges with different aspect ratio

\begin{tabular}{lccccc}
\hline Aspect ratio(a/b) & Mode 1 & Mode 2 & Mode 3 & Mode 4 & Mode 5 \\
\hline 0.5 & 8.008 & 9.065 & 9.768 & 14.389 & 14.786 \\
1 & 20.743 & 26.640 & 30.891 & 32.873 & 34.756 \\
1.5 & 41.957 & 53.737 & 53.821 & 54.122 & 66.356 \\
2 & 59.629 & 72.969 & 74.515 & 81.248 & 100.637 \\
\hline
\end{tabular}


Table 7 and Fig. 11 shows the variation of first five mode of non-dimensional frequency parameter for different aspect ratio at CCCC boundary condition for eccentrically stiffened isotropic plate with central stiffener. Table 8 and Fig. 12 show the variation of first five mode of non-dimensional frequency parameter for different aspect ratio at CCCC boundary condition for concentrically stiffened isotropic plate with central stiffener. In both the tables and figures the variation of first five non dimensional frequency parameter at fully clamped boundary condition has increases as aspect ratio increases and maximum set of values are obtained for aspect ratio 2 and minimum set of values are obtained for aspect ratio of 0.5 . Table 9 and Fig. 13 show the variation of first five mode of non-dimensional frequency parameter for different aspect ratio at CCCC boundary condition for eccentrically stiffened plate with double stiffener and Table 10 and Fig. 14 show the variation of first five mode of nondimensional frequency parameter for different aspect ratio at CCCC boundary condition for concentrically stiffened isotropic plate with double stiffener also shows the same trend of set of values but magnitude of values are moderate in comparison with the Table 7 and Fig. 11 and Table 8 and Fig. 12. Comparison of eccentric and concentric stiffened isotropic plate on non-dimensional frequency parameters are presented in the following Tables and Figures.

Table 11. Variation of non-dimensional frequency parameter of a clamped square isotropic plate for concentric and eccentric stiffeners at different modes

\begin{tabular}{lcccc}
\hline & \multicolumn{4}{c}{ Non dimensional frequency parameter } \\
Stiffener & \multicolumn{2}{c}{ Central Stiffener } & \multicolumn{2}{c}{ Double Stiffener } \\
\hline Mode number & Eccentric & Concentric & Eccentric & Concentric \\
\hline Mode 1 & 12.388 & 12.876 & 20.230 & 20.743 \\
Mode 2 & 15.466 & 15.775 & 26.557 & 26.640 \\
Mode 3 & 18.650 & 19.226 & 28.958 & 30.891 \\
Mode 4 & 20.363 & 20.473 & 30.041 & 32.873 \\
Mode 5 & 27.680 & 28.065 & 33.730 & 34.756 \\
\hline
\end{tabular}

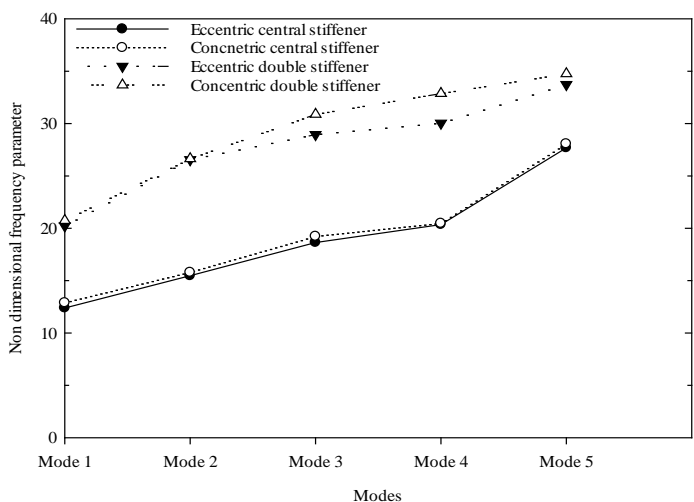

Fig. 15. Variation of non-dimensional frequency parameter of a clamped square isotropic plate for concentric and eccentric stiffeners at different modes

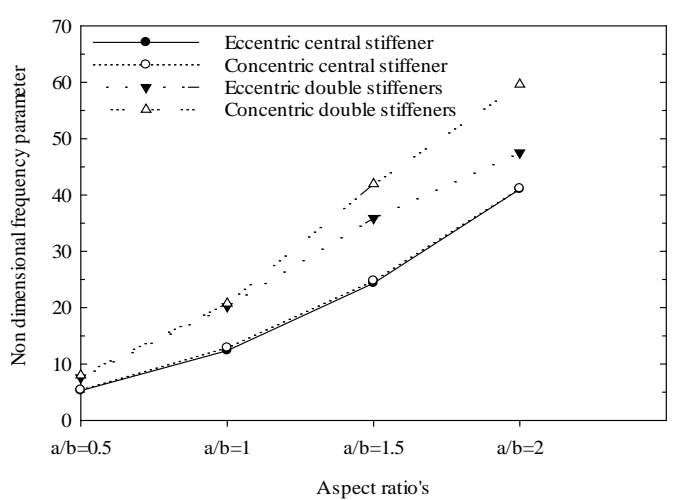

Fig. 16. Variation of non-dimensional frequency parameter of a clamped isotropic plate with concentric and eccentric stiffeners for different aspect ratios at mode 1 
To investigate the effect of eccentricity on the free vibration of stiffened plates, a fully clamped square plate with one, two stiffeners has been analyzed for both concentric and eccentric types at different mode shapes. The results obtained from such case are presented in Table 11 and Fig. 15. The effect of eccentricity on non-dimensional frequency parameter has been observed. It is interesting to note that the addition of eccentricity does affect the values of non-dimensional frequency parameter on the clamped plate with merely one stiffener. As the number of stiffener increase effect of eccentricity affect the values of non-dimensional frequency parameter but the magnitude of difference is small.

Table 12. Variation of non-dimensional frequency parameter of a clamped isotropic plate with concentric and eccentric stiffeners for different aspect ratios at mode 1

\begin{tabular}{lcccc}
\hline & \multicolumn{3}{c}{ Non dimensional frequency parameter } \\
\hline Stiffener & \multicolumn{2}{c}{ Central Stiffener } & \multicolumn{2}{c}{ Double Stiffener } \\
\hline Aspect ratio a/b & Eccentric & Concentric & Eccentric & Concentric \\
\hline 0.5 & 5.290 & 5.402 & 7.588 & 8.008 \\
1 & 12.388 & 12.876 & 20.23 & 20.743 \\
1.5 & 24.345 & 24.770 & 35.863 & 41.957 \\
2 & 41.053 & 41.165 & 47.527 & 59.629 \\
\hline
\end{tabular}

To investigate the effect of eccentricity on the free vibration of stiffened plates, a fully clamped square plate with one, two and three stiffeners has been analyzed for both concentric and eccentric types for different aspect ratios at mode 1 . The results obtained from such case are presented in Table 12 and Fig. 16. The effect of eccentricity on non-dimensional frequency parameter has been observed. It is interesting to note that the addition of eccentricity does affect the values of non-dimensional frequency parameter on the clamped plate with merely one stiffener on increasing aspect ratios. As the number of stiffener increase and aspect ratio's increases effect of eccentricity affect the values of non-dimensional frequency parameter but the magnitude of difference is moderate.

Table 13. Variation of non-dimensional frequency parameter of an isotropic square plate with concentric and eccentric stiffeners for different boundary conditions at mode 1

Non dimensional frequency parameter

\begin{tabular}{lcccc}
\hline Stiffener & \multicolumn{2}{c}{ Central Stiffener } & \multicolumn{2}{c}{ Double Stiffener } \\
\hline Boundary condition & Eccentric & Concentric & Eccentric & Concentric \\
\hline CCCC & 12.388 & 12.876 & 20.23 & 20.743 \\
SSSS & 9.441 & 9.712 & 17.32 & 17.196 \\
CSCS & 10.064 & 10.517 & 18.35 & 18.923 \\
CFCF & 4.438 & 4.567 & 6.29 & 6.578 \\
CFFF & 1.564 & 1.713 & 3.552 & 3.831 \\
\hline
\end{tabular}

To investigate the effect of eccentricity on the free vibration of stiffened plates, a fully clamped square plate with one, two and three stiffeners has been analyzed for both concentric and eccentric types for different boundary condition at mode 1 . The results obtained from such case are presented in Table 13 and Fig. 17. The effect of eccentricity on non-dimensional frequency parameter has been observed. It is interesting to note that the addition of eccentricity does affect the values of nondimensional frequency parameter on the clamped plate with central stiffener and double stiffener. 


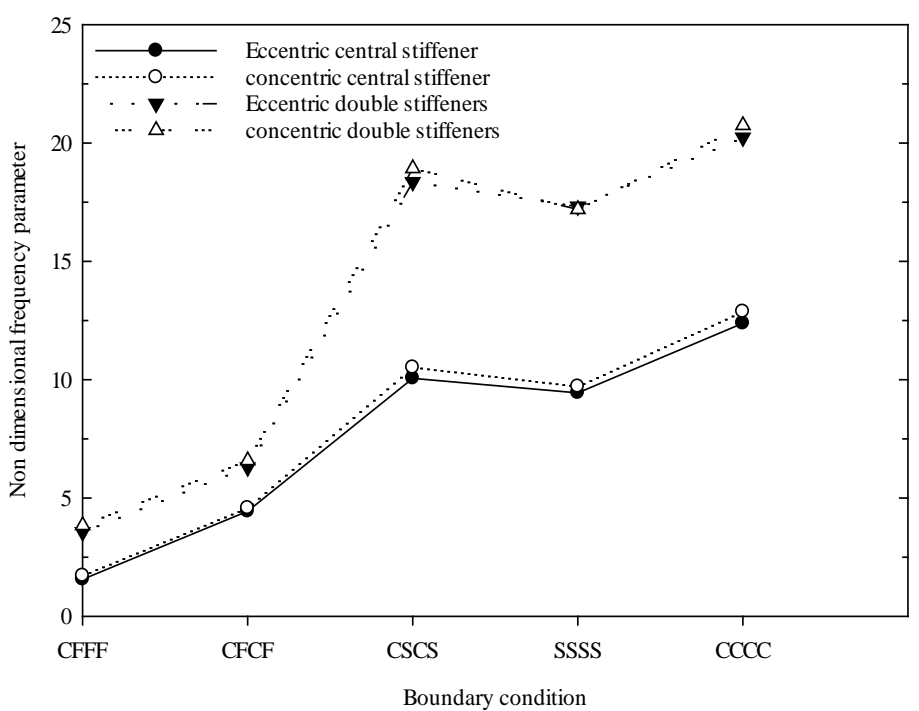

Fig. 17. Variation of non-dimensional frequency parameter of a square isotropic plate with concentric and eccentric stiffeners for different boundary conditions at mode shape 1

\section{Conclusions}

In this paper free vibration analysis of eccentric and concentric stiffened isotropic plate has been studied using ANSYS (APDL). Convergence study of eccentrically stiffened plate has been obtained. From the present analysis it is observed that comparison with available literature gives the result with in moderate and satisfactory range. From the result it is observed that non dimensional frequency parameter increases as aspect ratio increases. Non dimensional frequency parameter is higher for fully clamped boundary condition in comparison to the other boundary conditions and lower for the CFFF boundary condition for both eccentrically and concentrically stiffened plate with central and double stiffener. Non dimensional frequencies are higher for fully clamped boundary condition for eccentric and concentric stiffened isotropic plate in comparison to other boundary condition. It is also seen that non dimensional frequencies are increases in a moderate value for eccentric and concentric isotopic plate with double stiffener in comparison to the central stiffener. It is interesting to note as the number of stiffener increase and aspect ratios increases effect of eccentricity affect the values of nondimensional frequency parameter but the magnitude of difference is moderate.

\section{References}

Aksu, G., \& Ali, R. (1976). Free vibration analysis of stiffened plates using finite difference method. Journal of Sound and Vibration, 48(1), 15-25.

Bathe, K. J. (1996). Finite element procedures. Prentie-Hall, Englewood cliffs.

Ebirim, S. I., Ezeh, J. C., \& Ibearugbulem, M. O. (2014). Free vibration analysis of isotopic rectangular plate with one edge free of support (CSCF and SCFC plate). International Journal of Engineering \& Technology, 3(1), 30-36.

Hamedani, S. J., Khedmati, M. R., \& Azkat, S. (2012). Vibration analysis of stiffened plates using Finite Element Method. Latin American Journal of Solids and Structures, 9(1), 1-20.

Holopainen, T. P. (1995). Finite element free vibration analysis of eccentrically stiffened plates. Computers \& Structures, 56(6), 993-1007.

Klitchieff, J. M., \& Belgrade, Y. (1949). On the stability of plates reinforced by ribs. ASME Journal of Applied Mechanics, 16, 74-76.

Long, B. R. (1968). Vibration of eccentrically stiffened plates. Shock and Vibration Bulletin, 38, 4553. 
Mukherjee, A., \& Mukhopadhyay, M. (1986). A review of dynamic behaviour of stiffened plates. The Shock and Vibration Digest, 18, 3-8.

Mukhopadhyay, M. (1989). Vibration and stability analysis of stiffened plates by semi-analytic finite difference method, part I: consideration of bending displacements only. Journal of Sound and Vibration, 130(1), 27-39.

Olson, M. D., \& Hazell, C. R. (1977). Vibration studies on some integral rib-stiffened plates. Journal of Sound and Vibration, 50(1), 43-61.

Qing, G., Qiu, J., \& Liu, Y. (2006). Free vibration analysis of stiffened laminated plates. International Journal of Solids and Structures, 43(6), 1357-1371.

Sadek, E. A., \& Tawfik, S. A. (2000). A finite element model for the analysis of stiffened laminated plates. Computers \& Structures, 75(4), 369-383.

Samanta, A., \& Mukhopadhyay, M. (2004). Free vibration analysis of stiffened shells by the finite element technique. European Journal of Mechanics-A/Solids, 23(1), 159-179.

Samaei, A. T., Aliha, M. R. M., \& Mirsayar, M. M. (2015). Frequency analysis of a graphene sheet embedded in an elastic medium with consideration of small scale. Materials Physics and Mechanics, 22, 125-135.

Thinh, T. I., \& Khoa, N. N. (2008). Free vibration analysis of stiffened laminated plates using a new stiffened element. Techniscme Mechanik, 28(3-4), 227-236.

Wah, T. (1964). Vibration of stiffened plates. Aeronautical Quarterly, 15, 285- 298.

Wu, J. R., \& Liu, W. H. (1988). Vibration of rectangular plates with edge restraints and intermediate stiffeners. Journal of Sound and Vibration, 123(1), 103-113.

Zeng, H., \& Bert, C. W. (2001). A differential quadrature analysis of vibration for rectangular stiffened plates. Journal of Sound and Vibration, 241(2), 247-252. 